\title{
Políticas de saúde e formação de recursos humanos em Odontologia
}

\author{
Os cursos de Odontologia devem avançar para um projeto pedagógico \\ construido coletivamente, centrado no aluno como sujeito da \\ aprendizagem e no professor como mediador do processo \\ ensino-aprendizagem.
}

Samuel Jorge Moysés*

\footnotetext{
* Professor Titular do Centro de Ciências Biológicas e da Saúde da Pontifícia Universidade Católica do Paraná.
}

$\mathbf{P}$ esquisa recente ${ }^{7}$, encomendada pelas principais entidades representativas da Odontologia no Brasil, revela aspectos relativos ao perfil atual do cirurgião-dentista brasileiro, bem como aponta tendências já exploradas em outras publicações que tratam do tema da inserção profissional do dentista no mercado de trabalho ${ }^{19}$.

Por exemplo, torna-se clara a progressiva feminização do trabalho, com predomínio de profissionais jovens, até 30 anos, com altíssima concentração na região sudeste, especialmente no estado de São Paulo, atuando como clínicos gerais e/ou especialistas nos seus consultórios, sendo que a maioria tem a autopercepção de que ainda são profissionais liberais autônomos.

Contudo, uma realidade mais típica das classes trabalhadoras assalariadas confronta esta autopercepção liberal dos dentistas. Mais de $40 \%$ deles declaram exercer uma jornada de trabalho igual ou maior de 44 horas semanais, $37 \%$ admitem duplo vínculo com emprego público ou privado, e mais de $48 \%$ deles admitem uma renda familiar máxima mensal de $\mathrm{R} \$ 3.600,00$. Um número bastante importante dos profissionais, exercendo a prática privada, também reconhece ser dependente dos convênios/credenciamentos, que poderiam ser percebidos como uma forma de "assalariamento indireto" exercido no próprio consultório privado, dada a grande dependência desta modalidade de vínculo na geração de "receita".

Mas não deveríamos nos iludir com estas elaborações simples e a natureza descritiva desta sondagem amostral do mercado de trabalho dos cirurgiões-dentistas brasileiros. Ela encerra amplas possibilidades de interpretação, que nos remetem ao debate contemporâneo sobre as profissões superiores, tanto no que diz respeito ao processo de formação e desenvolvimento desta forma de organização da divisão social do trabalho, quanto aos enfoques sobre as profissões no mercado.

\section{CONJUNTURA CRÍtICA}

O Brasil saltou de 90 cursos de Odontologia ofertados em 1996 para 165 cursos em 2003. Neste período, enquanto a população brasileira cresceu a uma proporção aproximada de $1,8 \%$ ao ano, o crescimento do número de cirurgiões-dentistas foi de cerca de $2,5 \%$ ao ano ${ }^{3,7}$. A estimativa atual é de que cerca de $30 \%$ da população brasileira tem acesso regular, anual, a serviços odontológicos, públicos e privados, mas certamente este percentual reduz bastante quando se considera apenas a população que, de fato, pode pagar os custos da atenção privada com recursos próprios. O Quadro 1, construído com base nas informações da Pesquisa Nacional por Amostra de Domicílios - PNAD/1998, pode ajudar a esclarecer esta questão ${ }^{4}$.

Com isto, sem contar os mais de 29 milhões de brasileiros que jamais obtiveram atenção odontológica, resta uma grande maioria, talvez na casa dos 100 milhões de cidadãos, que acessam de modo esporádico os serviços de Odontologia, considerando os dois cortes de faixa de renda exemplificados no Quadro 1. Predominam nesta situação aqueles de renda inferior a 10 salários mínimos. O grande desafio, então, é incluir este enorme contingente, que potencialmente estaria enquadrado na categoria de "população SUS- 
Quadro 1 - Relação entre população, renda e acesso a serviços odontológicos no Brasil (PNAD $\left.{ }^{4}, 1998\right)$.

\begin{tabular}{|c|c|c|c|}
\hline População & Número (milhões) & $\%$ relativa à faixa de renda & $\%$ do total \\
\hline Total & 158.232 .252 & & 100,0 \\
\hline Nunca consultou dentista & 29.626 .264 & & 18,7 \\
\hline Com acesso a dentista, em qualquer tempo & 128.526 .924 & & 81,3 \\
\hline População com renda declarada < 10 salários mínimos & 122.247 .173 & & 77,3 \\
\hline $\begin{array}{l}\text { Populaçãocom renda declarada < } 10 \text { salários mínimos } \\
\text { e com acesso a dentista no último ano }\end{array}$ & 34.786 .697 & 28,5 & 22,0 \\
\hline População com renda declarada > 10 salários mínimos & 27.059 .005 & & 17,1 \\
\hline $\begin{array}{l}\text { População com renda declarada > } 10 \text { salários mínimos } \\
\text { e com acesso a dentista no último ano }\end{array}$ & 14.909 .675 & 55,1 & 9,4 \\
\hline
\end{tabular}

dependente", portanto condicionado à existência de políticas públicas de saúde dentro do Sistema Único de Saúde (SUS).

Estimativamente, apenas o contingente de renda acima de 10 salários mínimos poderia sustentar o custo da atenção odontológica privada, de forma regular. Mas estes não passam de $9,4 \%$ da população pesquisada na PNAD/1998. Por outro lado, a população coberta por planos de saúde odontológicos, conforme recentes projeções, não passa de $1,5 \%^{2}$. Daqueles regularmente atendidos, na faixa abaixo de 10 salários mínimos, possivelmente a maioria foi atendida na rede pública.

Como resolver este paradoxo, de cirurgiões-dentistas progressivamente sem "pacientes", nos seus consultórios, e uma população sem (ou com acesso irregular) a dentistas? Para isto, profundas mudanças sociopolíticas, conceituais, pedagógicas e práticas tornam-se necessárias para a Odontologia brasileira. Novos papéis profissionais são exigidos do cirurgião-dentista.

Para discutir tais questões com o mínimo de sustentação analítica, será preciso recorrer a alguns dos teóricos da Sociologia das Profissões, já que os fatores que influenciam a emergência de novas profissões, ou "inovações" por dentro das profissões tradicionais, podem ser:

- avanço do conhecimento;

- progresso tecnológico;

- mercado;

- estrutura de serviços;

- políticas públicas;

- agenda social e perfil de demandas.

\section{UMA BREVE INCURSÃO NA SOCIOLOGIA DAS PROFISSÕES}

Estudos sobre profissões constituem, nas Ciências Sociais, um alentado segmento. Já há importante aná- lise publicada, na Sociologia das Profissões, focando tanto as profissões no mercado e sua constituição em grupos sociais, quanto suas relações com o Estado e com a sociedade, nas perspectivas histórica, comparada ou contemporânea ${ }^{6}$.

Diante da prevalência de estudos sobre ocupações pouco ou semiqualificadas na Sociologia do Trabalho brasileira, surge um novo campo temático dos estudos sobre profissões de nível superior, especialmente quanto a trajetórias de profissionalização. Alguns vêem, por exemplo, uma tentativa de legitimar a usurpação de posições privilegiadas neste mesmo mundo do trabalho, por meio de credenciais (credencialismo) e do corporativismo. O credencialismo é um conceito de inspiração weberiana desenvolvido para se referir à "utilização inflacionada dos certificados educacionais como meio de monitorizar a entrada para posições-chave na divisão do trabalho" ${ }^{20}$.

Esta corrente teoriza sobre questões que teriam suas correspondentes expressões de senso comum, na linguagem popular, em frases como: "A corporação contra a sociedade"; ou ainda (e especialmente) no caso brasileiro: "Você sabe com quem está falando?", típica dos que brandem diplomas e títulos no mundo das profissões superiores (ou, ainda, de modo mais tragicômico, na política).

Na dimensão do mercado surgem estudos que refletem sobre o sucesso ou insucesso da profissionalização no Brasil, tais como as análises que identificam o poder dos profissionais, as que apontam as fraquezas para obter ou manter o monopólio do mercado de trabalho, as que analisam os processos de construção das profissões envolvendo o controle das credenciais, os abrigos de mercado, o encarceramento dos saberes, e as estratégias atuais que visam criar "blindagens" contra o risco de desprofissionalização.

Na dimensão das relações entre profissões e Estado, há uma ênfase nos estudos que analisam as profis- 
sões na política, sua participação na esfera pública, a atuação de seus membros como profissionais no Estado ou como "experts" qualificados para assessorá-lo, as visões que concebem os profissionais como construtores do Estado, a perda da autonomia em decorrência da relação com o Estado e da profissionalização vinda de cima para baixo, bem como a cooptação dos profissionais.

Há, também, análises que focalizam as profissões na sociedade, tanto aquelas que vinculam as profissões com a estrutura da sociedade quanto as que buscam compreender os projetos e as ideologias profissionais voltados para a sociedade civil e para a cidadania. E também os estudos sobre feminização de carreiras profissionais, sobre socialização e identidade profissionais, sobre "ethos" dos grupos profissionais no Brasil, sobre profissões e imigração e sobre profissões e mobilidade social.

Seriam os profissionais os novos mandarins da sociedade contemporânea ou estariam se proletarizando? Esta questão, aparentemente simples de observar, traz consigo a necessidade de focalizar uma visão crítica sobre o conceito de profissão.

Um dos aspectos mais característicos da expansão e diversificação da estrutura ocupacional no Brasil é o crescimento do número de ocupações que requerem o nível superior de educação: em 1950 seriam menos que uma dezena as profissões estabelecidas; em 1980 eram 114, das quais 76 estavam regulamentadas. Atualmente, no setor saúde, são 14 profissões superiores reconhecidas pelo Conselho Nacional de Saúde (Resolução no 287 de 08 de outubro de 1998). Esta expansão quantitativa é mais impressionante quando vista sob o ângulo do contingente de profissionais no mercado de trabalho: em 1979, a força de trabalho com educação de nível superior constituía $3,5 \%$ da população economicamente ativa, contra 5,35 em $1985^{9}$.

Paralelamente ao surgimento de novas profissões, aquelas chamadas "tradicionais" - Medicina, Odontologia, Engenharia ou Direito - foram se fragmentando em inúmeras especialidades: o clínico geral e o engenheiro civil, os profissionais polivalentes foram suplantados por dezenas de especialistas. Por trás desta explosão está a expansão vertiginosa do sistema de ensino superior, principalmente a partir da Reforma Universitária de 1968. O afluxo de sucessivas ondas de jovens em busca do diploma universitário, talvez mais do que as exigências da divisão social do trabalho, forçou a ampliação do número de carreiras disponíveis. Ano após ano as universidades - e as faculdades isoladas que foram surgindo por todo o País - jogaram no mercado de trabalho milhares de novos profissionais. Termos como "inflação de diplomas" começaram a circular como um alarme contra a desvalorização dos graus acadêmicos; outros, como "credencialismo", para denunciar o ensino superior como mera fábrica de "sinalizadores" para um mercado de trabalho muito competitivo, independentemente do conteúdo da educação.

Diniz $^{9}$ (2001) analisa as questões acima sob três aspectos:

a) Quais os modelos analíticos disponíveis para o estudo das profissões, e como encaminham a análise da constituição das categorias ocupacionais?

b) Qual a consistência do argumento sobre "proletarização" e a "desprofissionalização", como antecipações do destino das profissões nas sociedades capitalistas contemporâneas?

c) Qual o papel das profissões nos processos de geração de desigualdades sociais? Segundo a autora, há que se olhar as profissões do ponto de vista de sua constituição, suas formas organizativas e suas estratégias de monopolização de mercado; e ressaltar a importância de se considerar a "cultura" das profissões no estudo do "lugar" das profissões na estratificação social.

Nesta linha, as evidências de crescente assalariamento de algumas das chamadas "profissões liberais" não constituem suporte adequado para a tese da "proletarização" dos profissionais. Utilizada no seu sentido mais simples, a expressão apontava para o que parecia ser uma importante transformação na esfera ocupacional. Por detrás do assalariamento alguns percebiam a lógica inexorável do capital (ou do Estado sob a égide do capital) que, finalmente, começava a subordinar aquelas ocupações que há poucas décadas eram autônomas e operavam à margem do sistema produtivo. Principalmente os médicos passaram a recorrer à imagem de uma "época dourada", lamentando a "mercantilização" da Medicina e a perda da antiga dignidade da profissão, ou para protestar contra a mediação de terceiros na relação "profissional-paciente", ou sua crescente subordinação a hierarquias empresariais e/ou estatais heterônomas. Aparentemente, investir numa educação longa e dispendiosa já não rendia os dividendos que todos esperavam ver agregados ao diploma universitário.

Estariam os profissionais descendo a ladeira que os levaria, mais cedo ou mais tarde, às mesmas condições daquela imensa parcela da força de trabalho que, além de assalariada, perdeu o controle sobre o processo do seu próprio trabalho? Muitos supõem que as ocupações que se tornaram "profissões" seguiram uma trajetória mais ou menos padronizada composta 
de sucessivas etapas de profissionalização. Em certo sentido, termos como "proletarização" e "desprofissionalização" - que não são exatamente equivalentes - apontam para um percurso invertido: ocupações profissionalizadas são impelidas, por diversos fatores, a se tornar "menos profissão". As dificuldades de um esquema desta espécie ficaram evidentes com a multiplicação de pesquisas históricas que mostram que as profissões percorrem trajetórias muito diferenciadas de sociedade para sociedade, e que as descontinuidades nestas trajetórias não são incomuns. A Engenharia brasileira teve a mesma trajetória da Medicina, ou da Odontologia? Qual foi o papel do Estado brasileiro na organização das profissões?

Outra questão diz respeito às classes sociais. Quando se discute a tese da "proletarização" e a inserção dos profissionais no sistema de estratificação social, as dificuldades tornam-se maiores. Serão as profissões meras ocupações? Grupos de status? Estratos dentro de classes? Uma classe social? Esta é uma questão difícil, e as respostas são as mais variadas mesmo dentro de uma única tradição analítica ${ }^{18}$. Neoweberianos não se entendem sobre o assunto, neomarxistas digladiamse em torno de diferentes mapas topográficos de estrutura de classe. As teorias das classes sociais compartilham de uma característica comum: uma classe é pensada como uma posição numa estrutura de diferenças, ou de posições. Seu sentido, seu poder descritivo, classificatório e analítico, constrói-se no cruzamento entre característicasintrínsecas e características diferenciais destas posições. Se, em Marx, o operário define-se pela liberdade em relação aos meios de produção, isto decorre de que outro, o capitalista, tem a propriedade destes. O operário define-se tanto por diferença (ele não é capitalista, não é servo, não é escravo) quanto por identidade (ele é livre, só tem sua força de trabalho para vender). As teorias de estratificação social de extração weberiana definem ainda mais fortemente a estrutura de classes como sendo de posições e diferenças, estas últimas quase sempre associadas a idéias de hierarquia e status social ${ }^{6}$.

De maneira geral, estas questões básicas, mas já centenárias na tradição crítica, são refratárias a consenso. Mais consensual é a constatação de que as profissões contribuem decisivamente, e de maneira peculiar, para a estrutura de desigualdades sociais. Desvendar os mecanismos pelas quais elas se apropriam de vantagens materiais e simbólicas é mais importante do que "ficar revolvendo a desorganizada mapoteca da teoria de classes".

Ao se olhar para o "lugar" ocupado pelos profissionais superiores na estratificação social, bem como sua respectiva cultura de atuação por dentro das instituições, percebe-se que eles ainda dispõem de recursos de poder, bem como uma ideologia corporativa difícil de colocá-los no mesmo patamar dos assalariados proletários, mesmo que a renda de certas profissões venha caindo na média. Isto parece ser verdadeiro, sobretudo na perspectiva da Sociologia crítica de conceitos como "trabalho" e "classe social".

$\operatorname{Diniz}^{9}$ (2001) também conclui que, embora as profissões possam ser veículo ou agência dos interesses de classes, esta função é mediada pelo interesse das profissões em manter seus monopólios no mercado de serviços e seu status na estrutura ocupacional. Mostra também que profissão e burocracia não são princípios conflitantes de organização do trabalho. Em várias sociedades a burocracia do Estado foi o modelo de organização das profissões.

Qual a participação do Estado na viabilização do profissionalismo, freqüentemente pensado como um processo que só ocorre no mercado? A relação com o Estado pode impulsionar o profissionalismo ou inviabilizar a noção de profissão, segundo as características das profissões que as diferenciariam das demais ocupações no conceito construído por Freidson ${ }^{12,13}$ (1994, 2001). Para este autor - que estudou, particularmente, o profissionalismo médico -, nas sociedades industrializadas os profissionais são valorizados e diferenciados de outros trabalhadores ligados as burocracias estatais ou regidos puramente pelo mercado, porque possuem conhecimentos e habilidades especializados. Ele apresenta o profissionalismo como um tipo ideal, fundado na economia política de linha weberiana. Para ele, na regulação de certas atividades humanas, o profissionalismo é uma "terceira lógica", uma opção mais viável do que o consumismo do mercado e a burocracia do Estado.

Contudo, Freidson ${ }^{12,13}(1994,2001)$ discute o propalado declínio do profissionalismo, nos dias atuais, predizendo um "renascimento" do mesmo. Mais que isto, o autor defende o profissionalismo como um método desejável de prover serviços complexos e discricionários para o público em geral, argumentando que métodos baseados puramente no mercado ou na burocracia de Estado empobreceriam a qualidade dos serviços aos consumidores. Nestes casos, estaria plenamente justificado o valor do "credencialismo" ou monopólio profissional, não obstante as críticas dos que ele qualifica como "economistas neoclássicos ou populistas".

Mas, segundo Campos (2001), o "crème de la crème" desta disputa deveria passar mesmo pela temática da inserção dos profissionais na estrutura de classe. 
Para ele, numa abordagem foucaultiana ${ }^{11}$, advogados, médicos, economistas, terapeutas, dentistas e tantos outros profissionais estão em tal extensão presentes em nossa vida cotidiana que não imaginamos que possam ser mais do que as aparências sugerem: não só os peritos a quem levamos os inevitáveis problemas que afligem todo cidadão, em troca de uma justa remuneração, mas também detentores de um poder sobre todos nós, os leigos, os não-iniciados nos insondáveis mistérios de corpos de conhecimento esotéricos.

Para Campos ${ }^{5}$ (2001), os profissionais podem também operar no atacado; médicos freqüentemente assessoram os governos no âmbito da saúde pública, ou os economistas cuidam da boa saúde das finanças nacionais. Mas a diferença aqui parece ser apenas de escala, pois a natureza do serviço permanece a mesma e idêntica à conduta que se espera dos profissionais; isto é, a prestação competente de um serviço, numa perspectiva como a de Max Weber, que tanta fé professou na racionalidade formal da técnica e da ciência.

O autor vai além e aponta criticamente a visão que tenta nos fazer crer que nosso clínico é um santo homem, imune aos apelos do vil metal, e que o nosso advogado é um ser absolutamente ético; e que à imagem deles, todas as demais espécies de profissionais interessam-se apenas pelo bem-estar dos clientes e da comunidade, em troca de justos e modestos honorários. Para ele, deveríamos prestar mais atenção na advertência de Bernard Shaw: "Toda profissão é uma conspiração contra o leigo" (All professions are conspiracies against the laity. The Doctor's Dilemma (1911) act. 1. [citado em 2004 jun 08] Disponível em: http://www.quotationspage.com/quotes/George_Bernard_ Shaw/71).

\section{ODONTOLOGIA E REALIDADE BRASILEIRA NA PASSAGEM DO SÉCULO XX PARA O SÉCULO XXI}

As contradições da Odontologia brasileira, observadas sob a perspectiva analítica da Sociologia das Profissões, refletem e reproduzem os dilemas correntes de um modelo de formação e prática odontológica imerso em complexa transição. A passagem da Odontologia de mercado, de natureza liberal e privada, típica das últimas décadas do século XX, para uma Odontologia sujeita às oscilações da oferta de emprego e renda, num mercado extremamente competitivo, é a tônica moderna.

Contribuem para esta paradoxal transição os descaminhos do sistema de educação superior no Brasil, particularmente na área da Saúde, bem como a inci- piente participação da Odontologia no SUS no Brasil. Além disto, o País atravessa uma importante transição demográfica e epidemiológica em saúde bucal, com o envelhecimento da população e o declínio de cárie em população jovem, não obstante persista o fenômeno da "polarização", com um percentual importante de crianças e adolescentes com alta experiência de cárie. Por outro lado, problemas ligados aos acidentes traumáticos em meios urbanos, que atingem as áreas de cabeça, face, boca e dentes, bem como a ocorrência do câncer bucal, tornam-se cada vez mais importantes. E, ainda mais, o adulto brasileiro continua portador de uma herança epidemiológica das mais graves, com grande estoque de doenças bucais acumuladas, refletidas no índice de edentulismo na terceira idade.

A realidade de fatos, acima referidos, impõe uma agenda de mudanças na formação e no trabalho do dentista brasileiro, já que o trabalho é a categoria central onde se encontram diferentes atores, provenientes de distintos espaços. As necessárias mudanças devem começar na formação profissional e na visão de mundo reproduzida dentro das academias, pois certamente nestes espaços também começa a formação das possibilidades para a empregabilidade futura do cirurgião-dentista e de sua relevância social ${ }^{17}$. O grande dilema para tratar de assuntos sensíveis como este é que toda mudança traz "desconforto".

Os Relatórios Flexner e Relatório Gies, publicados nos Estados Unidos, respectivamente em 1910 e 1926, normatizaram o ensino médico-odontológico. Os (des)caminhos médico-odontológicos, desde então, foram diversos. A concepção mecanicista, com redução da doença à dimensão biológica, levou a maior ênfase no processo curativo-reparador, o que gerou uma prática de alto custo, baixa cobertura, com pouco impacto epidemiológico e desigualdades no acesso.

Sobre a formação tradicional do dentista brasileiro, poderíamos começar falando de seu viés mais importante, implicado com o racionalismo dominante nas universidades brasileiras. Este viés poderia ser qualificado com o seguinte epíteto: o "erro" de Descartes.

Ou seja, o paradigma cartesiano disjuntivo, aplicado ao pensamento e a ação, com a separação do todo em partes e as demais dissociações decorrentes: sujeito/objeto, alma/corpo, espírito/matéria, qualidade/ quantidade, sentimento/razão, existência/essência, liberdade/determinismo. Este paradigma, aplicado aos currículos e disciplinas do meio biomédico, após as sucessivas reformas de natureza flexneriana/giesia- 
na, levou à ênfase ao domínio cognitivo e instrumental, com algumas das seguintes conseqüências: mecanicismo, biologicismo, assistência individual, especialização precoce, tecnificação do ato médicoodontológico, ênfase em Medicina/Odontologia curativa.

Um dos problemas mais visíveis do paradigma disjuntivo, quando aplicado ao mundo do trabalho e aos sistemas de saúde, aqui incluindo o sistema de formação de força de trabalho, é a separação, por oposição, das esferas público-estatal e privada como pólos que se repelem. Assim, geram uma ruptura, na organização objetiva do sistema e nas estruturas mais profundas onde as práticas sociais são representadas (intersubjetividade). O pensamento cartesiano típico tem como característica uma estrutura rígida de concepção do mundo, com a negação da diversidade, o uso de um repertório de certezas preestabelecidas e irrefletidas, produzindo, ao fim e ao cabo, uma postura intransitiva.

Exemplos do pensamento intransitivo na Odontologia podem ser citados pela construção de "personagens" do SUS, segundo esta ótica caricata. Portanto, quem seriam os trabalhadores ou gestores em serviços de saúde coletiva, senão o "esquerdista", o profissional "que não deu certo" no mercado, o "sacerdote", o monge franciscano, o "rebelde" sem causa. E, assim, fechando o ciclo dos pré-conceitos, os usuários do SUS nada mais são senão "carentes".

Mas qual é o impacto do projeto pedagógico na profissão odontológica? E mais: vivemos, de fato uma crise da Odontologia, ou uma crise da Odontologia de mercado? Para começar a responder esta formulação, poderíamos propor em nossa arquitetura conceitual a noção de que é fundamental formar força de trabalho em Odontologia, com vistas ao SUS e, dentro da lógica de reestruturação da atenção no SUS, trabalhar a própria abordagem familiar em programas como o Programa Saúde da Família (PSF).

Primeiro, porque parece estar caminhando para rápido esgotamento o modelo que alimentou o ensino e prática para gerações de dentistas/professores até meados dos anos 1990. São milhares de profissionais da nova geração vivendo o efeito arrasador da ocupação precária, que favorece uma crescente "canibalização" profissional, fora mesmo dos regramentos de mercado (por exemplo, com graves desvios de ética corporativa). Do ponto de vista da ética maior, de inclusão social e sanitária, são milhões de brasileiros sem respostas aos seus problemas de saúde bucal. A mutilação bucal ou a falta de acesso a serviços de qualidade é um sintoma da sociedade da exclusão e da barbárie.

Segundo, porque o modelo ainda dominante, sob a lógica da competência técnica para o mercado privado e para a ação "curadora", não produz sujeitos políticos capazes de protagonizar novas aberturas para a sociedade e para a profissão.

Finalmente, o SUS tem pressa para mudar o modelo de atenção dominante, ou seja, um projeto que seja distinto do modelo biomédico hegemônico e não pode continuar consumindo recursos no esforço de "(des)construção" de perfis profissionais inadequados, por meio de cursos de capacitação que visam fornecer o que as graduações não ofereceram. Infelizmente, a universidade não faz "recall" dos "produtos" que lança no mercado de trabalho.

As ideologias ocupacionais e o imaginário social do aluno/dentista, reforçados por uma concepção de ensino aprisionada em contextos de décadas passadas, criaram uma bomba-relógio de expectativas frustradas. Certamente, continua indispensável a competência no domínio de aspectos biológicos e clínicos envolvidos na prática profissional, mas também é cada vez mais premente o necessário desenvolvimento de competências quanto às dimensões ética, política, econômica, cultural e social do seu trabalho. O foco deve ser deslocado para a promoção de saúde, no seu sentido integral que inclui até mesmo a redução de danos, mas com aptidões para trabalhar na saúde coletiva, familiar e individual. Assim, o papel tradicionalmente atribuído pelo "mercado" ao dentista deve ser progressivamente substituído por novos papéis, com um retorno radical e historicamente contextualizado à agenda da Reforma Sanitária Brasileira.

Esta é uma difícil empreitada, já que é uma mudança substantiva, que implica em profunda revisão de conceitos e condutas daqueles responsáveis por coordenar e ministrar o ensino superior. Este novo protagonismo gera desconforto, desconfiança, reação conservadora e posicionamentos pessoais insólitos. Mas é neste quadro de pluralidade que as inovações ocorrem, e há muito que se comemorar também, país afora, em termos de projetos pedagógicos conseqüentes e fortes alianças transformadoras.

A questão colocada agora, no Brasil e no Ocidente, é ainda aquela já colocada anteriormente por pensadores como Paulo Freire ou Florestan Fernandes: a busca de uma educação libertadora, emancipatória, crítica e que nos leve a novos patamares de civilização. Estes pensadores advertiam que antes de decidirmos pelo tipo de universidade que queremos edificar é necessário refletir sobre o modelo de sociedade que desejamos desenvolver. E mais: 
"Não se pode esquecer que a história é cruel com aqueles que pensam que ela é eterna. Porque ela não é eterna. Ela muda as faces, muda as exigências. E pode se converter num abismo e afogar aqueles que não perceberem que é momento de mudar de rumo" ${ }^{\prime \prime}$.

Os grande pilares, ou fundamentos teóricos para mudança, estão sendo discutidos em grandes fóruns mundiais e já mostram suficiente clareza de orientação. Por exemplo, a Declaração de Paris ${ }^{22}$, que enfatiza a universidade como espaço que:

- propicie o aprendizado permanente;

- contribua para a consolidação da cidadania democrática;

- reforce suas funções críticas e progressistas;

- utilize sua capacidade intelectual e prestígio moral para defender e difundir ativamente valores humanistas;

- aporte sua contribuição para o tratamento dos problemas que afetam o bem-estar das comunidades onde atua;

- fomente a inovação e a transdisciplinaridade.

A Conferência Mundial da UNESCO, de onde emergiu a Declaração de Paris em 1998, foi recentemente reeditada em 2003, com o nome de Paris +5 . Reuniu cerca de 400 especialistas de 120 países para avaliar as mudanças ocorridas no ensino superior e fazer um balanço dos resultados obtidos desde a primeira reunião, em 1998. Neste evento, na conferência de abertura, o Ministro da Educação do Brasil reafirmou a visão de que a Universidade é a instituição mais preparada para reorientar o futuro da humanidade.

Mas, para tanto, há certamente um pressuposto crítico. Será preciso resgatar Paulo Freire e transformar o modelo "bancário", onde o aluno é mero "depositário do processo ensino-aprendizagem, exigindo a problematização, a ação e a reflexão do aprendiz sobre a realidade, bem como a capacidade de solucionar problemas reais"14,21. Os desdobramentos para tal movimento de mudança são:

- Superar as concepções antigas e herméticas das grades curriculares, muitas vezes, meros instrumentos de transmissão de conhecimento e informações, preparando o futuro graduado para enfrentar os desafios das rápidas transformações da sociedade, do mercado de trabalho e das condições de exercício profissional. Isto exige, não apenas alterar grades disciplinares em currículos estanques, mas uma profunda revisão de projetos pedagógicos que sejam mais dinâmicos, críticos, flexíveis, transdisciplinares.
- Promover no estudante a competência do desenvolvimento intelectual e profissional autônomo e permanente. Esta competência permite a continuidade do processo de formação acadêmica e/ou profissional, que não termina com a concessão do diploma de graduação, implicando em uma relação continuada com os centros formadores e uma educação permanente do sujeito que aprende.

- Nas escolas técnicas, ou nos cursos de graduação e pós-graduação em saúde, articular a Educação e a Saúde, com ênfase na promoção, prevenção, recuperação e reabilitação da saúde, em cenários pedagógicos diversificados, especialmente as próprias unidades públicas de saúde e seus respectivos territórios de cobertura. Desta forma, o conceito de saúde e os princípios e diretrizes do SUS são elementos fundamentais a serem enfatizados.

Não é por ausência de arcabouço teórico-legal, que tais dispositivos de mudança na realidade educacional do País deixarão de ocorrer. Reza a Constituição Federal do Brasil, de 1988:

- Título VIII - Da Ordem Social

- Capítulo II - Da Seguridade Social

- Seção II - Da Saúde

- Art. 200. Ao Sistema Único de Saúde compete, além de outras atribuições, nos termos da lei: III - ordenar a formação de recursos humanos na área de Saúde.

A Lei de Diretrizes e Bases (LDB), nº 9.394, de 20 de dezembro de 1996, também estabelece, em consonância com os dispositivos constitucionais:

- Estímulo à formação profissional generalista, humanista, crítica e reflexiva, com base no rigor tecnocientífico, pautado em princípios éticos e compromisso social.

- Perfil profissional com foco na promoção de saúde e apto a trabalhar na saúde coletiva.

- Aluno que busca a aprendizagem ativa, que pode ser obtido por meio de atividades de extensão comunitária.

\section{CONCLUSÃO}

As profissões na pós-modernidade sofrem desgaste incontido, tanto mais quanto mais estiverem inseridas na dinâmica disruptiva do conhecimento. Do ponto de vista de mercado, a vantagem educacional comparativa é aquela que forma profissionais capazes de refazer constantemente a própria profissão. Do ponto de vista da vida, trata-se de gestar cidadãos capazes de mudar a sociedade em nome do bem co- 
mum ${ }^{8}$.

Portanto, os cursos de Odontologia deverão, progressivamente, avançar para um projeto pedagógico construído coletivamente, centrado no aluno como sujeito da aprendizagem e apoiado no professor como facilitador e mediador do processo ensino-aprendizagem, em conformidade com as resoluções recentes do Conselho Nacional de Educação ${ }^{1}$.

São aspectos cruciais para a educação superior, para a formação profissional e para uma cidadania contextualizada, particularmente quanto à Odontologia:

- o perfil do formando (egresso/profissional);

- as competências, aptidões e habilidades que lhe são necessárias;

- os conteúdos curriculares;

- os estágios e atividades complementares;

- a organização do curso;

- o acompanhamento e a avaliação.

As mudanças epistemológicas e metodológicas que ocorrem no campo da avaliação curricular procuram esclarecer a influência da condição pós-moderna na emergência de um novo paradigma. $\mathrm{O}$ alargamento do conceito de racionalidade - racionalidade comunicativa - e a teoria dos interesses cognitivos, na linha habermasiana ${ }^{15}$, mais as contribuições teóricas na linha do humanismo dos novos paradigmas educacionais ${ }^{16}$, permitem pensar em uma avaliação curricular que deixará de ser um mecanismo de regulação externa para passar a ser um processo participativo de construção de significados, única forma de fundar uma verdadeira cultura colaborativa que vá ao encontro dos novos desafios da Odontologia brasileira e das demandas sociais por mais saúde bucal.

\section{REFERÊNCIAS BIBLIOGRÁFICAS}

1. Brasil. Ministério da Educação. Conselho Nacional de Educação. Câmara de Educação Superior. Diretrizes Curriculares Nacionais do Curso de Graduação em Odontologia. Diário Oficial da União, Brasília, 4 mar 2002, seção 1, p. 10.

2. Brasil. ANSS -Agência Nacional de Saúde Suplementar. [citado 2002 dez 14] Disponível em: http://www.ans.gov.br/portal/site/ mapa_site/mapa_site.asp.

3. Brasil. IBGE - Instituto Brasileiro de Geografia e Estatística. [citado 2003 out 29] Disponível em: http://www.ibge.gov.br/ home/estatistica/populacao/censohistorico/default.shtm.

4. Brasil. PNAD - Pesquisa Nacional por Amostra de Domicílios, 1998. [citado 2003 out 29] Disponível em: http://www.ibge.gov. br/home/estatistica/populacao/trabalhoerendimento/pnad98/saude/ sb11.shtm.

5. Campos E. Prefácio. In: Diniz M (ed.). Os donos do saber: profissões e monopólios profissionais. Rio de Janeiro: Revan e IUPERJ/UCAN; 2001. p. v-viii.

6. Cardoso AM. GT trabalho e sociedade. [citado em 2001 nov 23] Disponível em: http://www.iuperj.br/associacao/anpocs/.

7. CFO - Conselho Federal de Odontologia. [citado 2003 out 30] Disponível em: http://www.cfo.org.br/.

8. Demo P. Complexidade e aprendizagem: a dinâmica não linear do conhecimento. São Paulo: Atlas; 2002. 195 p.

9. Diniz M. Os donos do saber: profissões e monopólios profissionais. Rio de Janeiro: Revan e IUPERJ/UCAN; 2001. 192 p.

10. Fernandes F. Entrevista. Tempo Social. Rev Sociol USP 1995;7(1-2):187-95.

11. Foucault M. The birth of the clinic: an archaeology of medical perception. New York: Vintage Books; 1994. 240 p.

12. Freidson E. Professionalism reborn: theory, prophecy, and policy. Chicago: The University of Chicago Press; 1994. 238 p.

13. Freidson E. Professionalism, the third logic: on the practice of knowledge. Chicago: The University of Chicago Press; 2001. 240 p.

14. Freire P. Pedagogia do oprimido. Rio de Janeiro: Paz e Terra; 1980. $220 \mathrm{p}$.

15. Habermas J. The theory of communicative action. v. 1 - Reason and the rationalization of society. Cambridge: Polity Press; 1995.

16. Morin E. Os sete saberes necessários à educação do futuro. São Paulo: Cortez, UNESCO; 2000. 118 p.

17. Moysés SJ. A humanização da educação em Odontologia. ProPosições/UNICAMP 2003;14(1):40-74.

18. Moysés SJ. Cooperativismo odontológico - uma face do mercado de trabalho do cirurgião-dentista. [Dissertação de Mestrado]. Natal: Universidade Federal do Rio Grande do Norte; 1989. $165 \mathrm{p}$.

19. Moysés SJ, Sheiham A. O papel dos profissionais de saúde bucal na promoção de saúde. In: Buischi YDP (Ed.). Promoção de saúde bucal na clínica odontológica. São Paulo: Artes Médicas/ APCD; 2000. p. 23-37.

20. Parkin F. Marxism and class theory: a bourgeois critique. Londres: Tavistock; $1979.54 \mathrm{p}$.

21. Taylor PV. The texts of Paulo Freire. Buckingham and Philadelphia: Open University Press; 1993. 169 p.

22. Universidade Federal do Paraná. A UNESCO e o futuro do ensino superior. Documentos da Conferência Mundial sobre a Educação Superior. Curitiba: Imprensa Universitária da UFPR; 1998. 75 p.

Aceito para publicação em 11/2003 